\title{
Class conditioning and class positioning in young people's everyday life with digital media
}

\author{
Exploring new forms of class-making \\ in the Swedish media welfare state
}

\section{Martin Danielsson}

School of Health and Welfare, Halmstad University, Sweden

\begin{abstract}
In this article, I explore how social class shapes the conditions and configurations of digital media practice in the everyday life of young people in Sweden. Drawing on Bourdieusian theory and qualitative interview data from two research projects, I complicate the notion of Sweden as a universally wired media welfare state by showing how economic and cultural forces are structuring Internet access and digital media practice along the lines of preexisting social divisions. Invoking Bourdieu's conceptualisation of social classes as defined both intrinsically and relationally, I identify and exemplify two different but interrelated processes whereby class makes a difference in young people's everyday relationship to digital media: class conditioning and class positioning. I conclude the article by arguing that distinguishing between these processes might offer a better understanding of the relationship between class and everyday media practice. The complexities of advancing a welfare-oriented media policy in the age of digital media are also discussed.
\end{abstract}

Keywords: social class, digital inequalities, young people, media practice, media policy

\section{Introduction}

The Swedish welfare state is frequently celebrated as a model society. Adhering to principles of universalism and the promotion of "an equality of the highest standards, not an equality of minimal needs" (Esping-Andersen, 1990: 27), it reflects a long-lasting political commitment to the welfare of all citizens. This commitment has produced several reforms in a wide range of policy fields throughout the years, which have resulted in low levels of socioeconomic inequality and high rates of upward social mobility (Erikson \& Goldthorpe, 1992; Hort, 2014; Therborn, 2018). Swedish media and Internet policy too have long been permeated and shaped by welfare ideals. For instance, the range of policy measures designed in the 1990 s, in order to counter the emergence of

Danielsson, M. (2021). Class conditioning and class positioning in young people's everyday life with digital media: Exploring new forms of class-making in the Swedish media welfare state. Nordicom Review, 42(S3), 150-162. https://doi.org/10.2478/nor-2021-0031 
digital inequalities as Sweden was heading its way into a post-industrial information society (see Olsson, 2002; Pettersson, 2001), implies an understanding of the Internet as a public good and a commitment to universal Internet access (Syvertsen et al., 2014). Similarly, when Swedish broadband expansion took off by the turn of the millennium, it was supported by the national government's vision of creating "an information society for everyone" (Government Offices of Sweden, 2000).

Twenty years later, this vision seems to be on the verge of realisation. About 90 per cent of the Swedish population can now access the Internet using a home computer, and most people have access to a laptop and other portable networked media devices (e.g., smartphones) as well (Nordicom, 2019). Many local governments have also decided to implement "one-to-one technologies" in public schools (i.e., one laptop or tablet per student), at least partially motivated by a wish to compensate for differences in access to home computers. While this might support the concept of Sweden as a media welfare state (Syvertsen et al., 2014), recent developments beyond the fields of media and Internet policy are complicating the story. Analogous to the extensive broadband expansion and rapid proliferation of networked home computers is also an unprecedented rise in socioeconomic inequality. Since the middle of the 1980s, the level of socioeconomic inequality has increased at a higher rate in Sweden than in any comparable country (Therborn, 2018), while upward social mobility has come to a halt (OECD, 2018). The welfare-oriented Internet policy measures have been accompanied by an erosion of redistributive economic policy, making it increasingly difficult to think of Sweden as an egalitarian model society.

It is also important in this context to consider the gap between policy and practice. Indeed, Swedish Internet policy has been successful in promoting the diffusion of personal computers and broadband Internet access, but as scholars on digital inequalities have emphasised, material access to the Internet constitutes a necessary, but not sufficient, condition for people to make use of it in meaningful ways. Not only is the question of material access more complex than just being a matter of having a networked computer in the household or not, but successfully engaging in various digital media practices also requires access to temporal resources and different cultural and social resources that are still unevenly distributed (Murdock et al., 1992; Robinson, 2009; Robinson \& Schulz, 2013; Selwyn, 2004; Warschauer, 2003; Zillien \& Hargittai, 2009). Internetstiftelsen [The Swedish Internet Foundation] (2019) estimates that more than a million Swedes are non- or low-users of the Internet, and even if most belong to the oldest population segments, age or generation cannot account for all variation.

It thus seems as if the Swedish Internet policy has succeeded in making Sweden a highly wired society, while it has failed in realising its professed welfare intentions. Not only are many Swedes still caught in the peripheries of information society, but more importantly, its premise that universal Internet access would promote upward social mobility and act as a safeguard against increasing levels of socioeconomic inequality seems to be an expression of wishful technological deterministic thinking (see Davies \& Eynon, 2018).

In this article, I explore the gap between the official Internet policy visions and the lived realities of those who have grown up in an increasingly wired, but at the same time divided, Swedish society. More specifically, my aim is to explore how social class shapes the conditions and configurations of digital media practice in the everyday life 
of young people in Sweden, drawing on the social theory of Pierre Bourdieu in general, and his conceptualisation of social classes as defined both intrinsically and relationally in particular (Bourdieu, 1987). Qualitative interview data from two different studies are used in order to exemplify and develop an argument about the benefits of making an analytical distinction between two interrelated processes whereby class makes a difference in young people's everyday relationship to digital media: class conditioning and class positioning.

Before describing these studies and turning to the analysis, I first discuss previous research on class-related digital inequalities among young people and the role of social class in shaping how digital media are incorporated in family life. This is followed by a brief presentation of Bourdieu's theory of social class and a discussion about the merits of Bourdieusian theory in qualitative research on everyday digital media practice.

\section{Young people, digital media, and social class}

There is a growing bulk of research on class-related digital inequalities among young people. As with digital inequalities research in general, most studies draw on survey data rather than in-depth interviews and ethnographic observations. These surveys have successfully evidenced and mapped the patterns of class-related digital inequalities among young people, consistently showing how those from the privileged classes are better off also when it comes to making full use of the Internet (Hargittai, 2010; Hargittai \& Hinnant, 2008; Livingstone \& Helsper, 2007). However, they provide limited insights into the contextually embedded mechanisms engendering this distinctive class pattern. As recently argued by Scheerder and colleagues (2019), the quantitative approach dominating this field of research has resulted in mainly descriptive studies with little explanatory power. Little is still known about how class-related digital inequalities occur and why.

Over the years, digital inequalities research has shifted its focus from mapping differences in Internet access and use to examining how such differences are associated with the development of digital skills and various ways of engaging with the Internet, including different outcomes of such engagement (Helsper \& Eynon, 2013; van Deursen et al., 2017). This shift is evident also in research on class-related digital inequalities among young people, and the development and distribution of digital skills seems to be an issue of special concern (Correa, 2016; Eynon \& Geniets, 2016; Gui \& Argentin, 2011). While this is an important question, as such skills are becoming increasingly indispensable, an exclusive focus on their preconditions, distribution patterns, and potential consequences runs the risk of overshadowing other aspects of digital inequalities, for example, how they are subjectively experienced and negotiated as part of everyday processes of social class.

However, knowledge about class-related digital inequalities among young people is not entirely based on quantitative research focusing on digital skills. Ethnographic research on digital inequalities has a long history (e.g., Schofield Clark et al., 2004), and qualitative approaches have produced detailed insights into the complex processes through which social class shapes young people's Internet access in everyday life as well as their digital media preferences and practices (Danielsson, 2014; Katz \& Gonzales, 2016; North et al., 2008; Robinson, 2009; Robinson \& Schulz, 2013). Several studies in this vein of research pay close attention to how such class-related processes are played 
out within the family and come to shape parents' and children's relationship to digital media and each other. Hollingworth and colleagues (2011) show how middle-class parents are familiar enough with technology to let their children learn to avoid online risks on their own, whereas working-class parents, in the light of such risks, tend to limit their children's Internet access or dissociate themselves from their use. They also show how working-class parents are more inclined to feel uncomfortable by the shifting power balance in the family caused by the digital skills of their children.

Similar findings are reported by Livingstone and colleagues (2015) as well as by Tripp (2010), who demonstrates how parents in low-income immigrant families in Los Angeles are torn between a belief in the Internet's educational potentials and a strong sense of anxiety about online risks, which trigger various restrictive parental mediation strategies regarding their children's Internet use. The children in these families thus enjoy limited opportunities for using the Internet in an open-ended and exploratory fashion. Drawing on Bourdieusian theory and a study on economically underprivileged teens in rural California, Robinson (2009) similarly shows how those with high-quality Internet access are allowed to develop a playful and exploratory approach to the Internet, whereas those with limited access tend to adopt a more instrumental approach or a "taste for the necessary", insofar as they are forced to reject the kind of online practices they are rejected, that is, practices of no immediate use.

Under conditions of abundant Internet access, qualitative studies have uncovered processes engendering a somewhat different class-related pattern. A recent Dutch study shows how highly educated parents consciously explore and reflect on possibilities and benefits associated with the Internet, but still try to postpone the moment when their children go online. Conversely, parents with lower education often depend on their children for assistance when using the Internet (Scheerder et al., 2019). Where Internet access is abundant in all strata of society, it thus seems as if privileged families too employ restrictive parental mediation strategies in order to regulate their children's Internet use, perhaps as a means for teaching self-discipline and engaging in class-related boundary-work (Danielsson, 2014; Lamont, 1992).

This article contributes to research on digital inequalities among young people by introducing a conceptual distinction between class conditioning and class positioning. This distinction is constructive for pinpointing the different but interrelated processes whereby class shapes young people's everyday life with digital media, and thus allows for a better understanding of the persistence of digital inequalities in highly wired societies such as Sweden. The next section briefly clarifies the roots of this conceptual distinction: Bourdieu's theory of social class.

\section{Theorising social class and media practice with Bourdieu}

A substantial part of Bourdieu's body of work is dedicated to explaining how social class relations are expressed and reproduced through cultural practices and institutions. Illustrative of his social theory at large, Bourdieu advocates a class analysis that considers the interplay between the objective and subjective dimensions of social class. He conceptualises society in terms of a multidimensional social space in which social agents and groups of agents occupy different social positions according to their total volume and composition of economic and cultural capital (Bourdieu, 1984). For Bourdieu, capital 
denotes resources of various kinds that are socially recognised, thus bestowing power upon their holder. Whereas economic capital refers to such things as income, wealth, and property rights, cultural capital is more complex, as it exists in an embodied, objectified, and institutionalised state and includes everything from cultural knowledge and taste to artefacts and educational qualifications. The structure of the distribution of these forms of capital constitutes the objective dimension of social class (Bourdieu, 1986). However, Bourdieu also argues that agents who share similar positions in social space - and thus are objectively subjected to similar conditions of existence - tend to acquire a similar class habitus, that is, a similar system of dispositions through which they subjectively perceive, orient themselves, and navigate social space in similar ways (Bourdieu, 1984). Hence, social class involves a subjective dimension too, and this is central to Bourdieu's explanation of how the objective class structure is reproduced.

Accordingly, Bourdieu (1987) conceptualises social classes, that is, sets of agents occupying different positions in social space, as defined both intrinsically and relationally. In other words, they are defined not only by the material conditions of existence and the conditionings associated with their different positions, but also by their position in relation to each other. Whether agents of a certain class feel they are above, below, or perhaps between agents of other classes is thus built into Bourdieu's (1984: 483) understanding of class: "A class is defined as much by its being-perceived as by its being [emphasis original]".

Bourdieu's recognition of the concurrent intrinsicality and relationality of social class informs the conceptual distinction between class conditioning and class positioning, introduced here as a way of identifying two different but interrelated processes whereby class makes a difference in young people's everyday relationship to digital media. While these concepts have not been used previously in studies of everyday media practice, they are recurrent in Bourdieusian research more generally. Conditioning is a term firmly rooted in Bourdieu's own writings, where it refers to the process through which different conditions of existence are internalised and come to shape different class habitus (Bourdieu, 1984). In order to describe how agents perceive and enact class relations through habitus, however, Bourdieu typically makes use of terms other than class positioning. For instance, he refers to "the work of class-making", denoting an "endless work of representation" through which "social agents try to impose their vision of the world or the vision of their own position in that world, and to define their social identity" (Bourdieu, 1987: 9-11). Nevertheless, "class positioning" is frequently used in research drawing on Bourdieu's social theory, referring either to abstract class position (e.g., Reay, 2004) or - which is the meaning employed here - the symbolic work of class-making that agents carry out in concrete social contexts (e.g., Snell, 2013).

Bourdieu himself paid limited attention to the media as an integral part of everyday life. Still, his social theory has long inspired media and audience researchers, including scholars on class-related digital inequalities (Danielsson, 2014; Hollingworth et al., 2011; North et al., 2008; Robinson, 2009; Zillien \& Hargittai, 2009). While theories developed in order to understand the conditions, workings, and effects of mass media have struggled to remain relevant as media environments are becoming increasingly complex and embedded in everyday life due to the proliferation of mobile and networked digital media, Bourdieu's conceptual toolkit has adapted more easily to a world where "media and communication technologies increasingly shape every sphere of social life from 
the global and public to the most intimate" (Livingstone, 2011: 1472). Bourdieu offers analytical tools for connecting not only media and the social, but also the different layers of mediatised social life. Putting these tools into qualitative research practice enables us to approach the seemingly mundane media practices of everyday life as involved in macrostructural power relations and processes, and it draws our attention to the possibility that young people's preferences and practices in relation to digital media might actually matter in terms of life-chances and future social position (Danielsson, 2014).

Moreover, Bourdieusian theory allows us to grasp digital media practice not as an exceptional kind of practice, but as a variety of practices among other cultural practices. It grants analytical sensitivity to differences in cultural value in this variety of digital media practices, but also to the ways in which the value of a particular digital media practice is recognised not only in relation to other digital media practices, or even media practices at large, but rather in relation to all kinds of everyday cultural practices. Contemporary media cultures are part of culture and society as a whole, and understanding the dynamic relationship between media and the social requires us to go beyond the narrow focus of media-centric and technological deterministic accounts and consider not only how digital media transform the arrangements of everyday life and the general organisation of society, but also how practices and cultures emerging in and around digital media become embedded in and shaped by historically constituted social and symbolic orders. Bourdieusian theory is helpful in this respect (Danielsson, 2014).

Finally, in allowing us to understand digital media practice as a variety of practices among other cultural practices, congregating into entire lifestyles, in Bourdieu's sense of the word - that is, lifestyles through which social power relations such as class are expressed and reproduced (Bourdieu, 1984) - Bourdieusian theory also supports critical interrogations of the association commonly made between digital innovation, young people, and social change (Danielsson, 2014). Originating in a kind of spontaneous technological deterministic thinking, this association is taken for granted in the widespread generational rhetoric about digital natives and digital immigrants (Prensky, 2001), but also in governmental Internet policy discourse where "digital upskilling the next generation" is often described as key for economic growth and increased social mobility (Davies \& Eynon, 2018).

\section{Notes on method and material}

This article draws on qualitative data from two different studies so that I may explore and exemplify class conditioning and class positioning as distinctive processes through which social class shapes the conditions and configurations of digital media practice in the everyday life of Swedish youth. The first study examines how class structures the digital media preferences and practices of young men from different class backgrounds and upper-secondary school study programmes. The empirical material was constructed through in-depth interviews with 34 young men (16-19 years old) in their schools, conducted during two phases between 2009 and 2011 at six schools located in Gothenburg and a rural municipality in southern Sweden. The young men were recruited strategically from both academically and vocationally oriented study programmes to ensure the inclusion, and possibility of comparing, participants occupying different positions in social space. Interviews were conducted in Swedish (all quotes have been translated 
by the author). The interplay between Bourdieusian theory and empirical data gradually resulted in a classification of participants based on their access to cultural capital in the family and their own educational and occupational aspirations. In this article, I simply distinguish between those rich and those poor in cultural capital.

Analytically, this study centred on how the digital media preferences and practices emanating from habitus are relationally configured in terms of class. Its empirical material allowed for detailed accounts of the media-related class positioning taking place in the interviews, but provided no more than glimpses into the ways in which processes of class conditioning are played out in the family and engender class-distinctive approaches to digital media. In order to turn such glimpses into insights, the second study sets out to explore the conditions and meanings of digital media practice in economically vulnerable families with children. This is an ongoing study, still in its embryonic stages. Only two interviews have been conducted, mainly due to difficulties in getting access to participants. These interviews too were conducted in Swedish. The first interview, carried out in 2016, involved Linda - a 42-year-old assistant nurse and a single mother of two children (aged 16 and 12) - whom I came in contact with through a public budget and debt counselling service. The second interview, conducted in 2017, included 31-yearold Hannah, a mother of five, and her eldest son Daniel (aged 15). At the time, Hannah was on parental leave with her two-week-old baby, but she was an assistant nurse by training and had a history of various healthcare employments. Her current partner was employed as a construction worker. I met Hannah and Daniel through a school-based project for strengthening the ties between Daniel's former school and the families living in its multi-ethnic, socioeconomically disadvantaged neighbourhood.

The second study thus builds on the first as part of an overall abductive research strategy, in which Bourdieusian theory is employed as an interpretative resource for providing deeper knowledge of how class matters in young people's everyday life with digital media, but also for supporting theory development in this field of research (see Danermark et al., 2019). The conceptual distinction between class conditioning and class positioning is the result of such interplay between theory and empirical data. The upcoming sections illustrate these concepts by examining examples from both studies, including participants occupying different positions in social space. By doing so, I want to shed light on the persistence of processes of class conditioning and class positioning over time, but also on the ways in which they operate at various levels of what Bourdieu (1984) calls "distance from necessity".

\section{Processes of class conditioning}

The concept of class conditioning centres on the process through which different material conditions of existence engender class-distinctive schemes of dispositions (i.e., different class habitus). In this empirical context, it grants analytical sensitivity to the ways in which the materialities of social class condition Internet access and digital media practice, but also to the certain conditionings vis-á-vis digital media springing from these circumstances.

For young people and parents positioned close to material necessity, such conditionings are usually articulated in a "taste for the necessary" (Bourdieu, 1984; Robinson, 2009). Thus, in the words of Bourdieu (1984), they tend to "refuse what they are refused" 
and "make a virtue of necessity". This is manifested in how some of the rural young men poor in cultural capital adjust to their limited broadband capacity and reject a digital lifestyle. It is evident also in how single-mother Linda - who struggles with economic hardships since her divorce and must make considerable sacrifices in order to secure equal digital opportunities for her kids - elaborates on her purchase of a mobile phone family subscription:

Well, they... It's not like I've been giving them [her kids] brand new mobiles, but more like they've taken over... how shall I put it? Initially I had my own mobile. Then they've taken it over when I got a new one. Because it has mainly been used for getting in touch with them. But I mean, you can use them for going online. It's not the latest gear, though [...] That's it. And they're happy with that [...] A lot of children got an iPhone 6 and, sure, there's a bit of nagging about that too, but if you can't, you can't [...] And I'm more like "but it works!" [...] I can't see why I should run to Telenor and trade myself up to an iPhone 6 just because it's possible to do so within the subscription. Sometimes you'll have to hold back a little [...] And now the iPhone 7 is out! If I'd given her an iPhone 6 then, she'd been nagging about an iPhone 7 now. It's like that all the time! "You have to keep up to date and be so..." [...] But they want it all, and it's impossible.

Material scarcity is sometimes manifested in a restricted living space, rather than limited access to the Internet and various networked media devices. Hannah and Daniel live in a media-rich home, but the four-room rented apartment is shared by two adults, five kids, and two dogs, creating a complex breeding ground for media-related conflicts. These conditions have left Hannah with little choice but to adopt a commanding parental mediation strategy regarding her children's digital media use, including strict rules and technical means for shutting down the broadband if they are violated.

Examples of parents forcefully trying to restrict their children's Internet access are rife among the narratives by the young men poor in cultural capital. Simon's mother, for example, cancelled the broadband altogether, as he was neglecting schoolwork, whereas Eddie's mother located the broadband modem in the hallway in order to easily turn it off if her son was chatting instead of studying and not obeying her verbal demands. Even if such instances of strict parental measures are not immediately attributable to material scarcity, they are nevertheless expressions of certain objective conditions of existence. These parents have no academic qualifications and usually hold working-class occupations where digital media technologies play a marginal role. Consequently, they are described by their sons as incompetent, reluctant, and suspicious when it comes to computers and the Internet. All in all, this makes them liable to adopt a highly restrictive parental mediation strategy, prioritising their children's obedience rather than their access to the Internet (see Hollingworth et al., 2011).

Positioned at a safe distance from material necessity, those rich in cultural capital can enjoy the Internet under somewhat different conditions. Not in the sense that their digital media practices are completely unrestricted, but because their highly educated parents are closely familiar with digital media technologies through their professional life, sudden parental shutdowns of the Internet are unlikely. Moreover, freedom from necessity means that these young men can benefit from the cultural capital accumulated within the family, through informal lessons in how to use the Internet in academically 
profitable ways. Here, 17-year-old Ian reflects on whether his Internet use has been shaped by growing up in an academic family:

Yes, I think that because... Especially my father, who is, well, highly educated... Using the Internet has always been essential to him, and he's always been very enthusiastic about it, so I think that he learned it straight away [...] And he is... well, the most efficient Google-person I know. He can google anything with just three words [...] He knows exactly what words to use, so he's always been showing the importance of learning it, and we've always had Internet at home, since... very early. So, I think it's like... you've grown up with someone who can actually use it as well [...] So that you don't have to learn everything on your own.

The class conditioning taking place through such informal training is further accentuated by Ian's way of describing his own online information-searching practices. There is a distinctive sense of ease and confidence in his accounts of how "it's easy to find different sources" and "assess the credibility of the information based on the sources". "Most of the time you find what you're looking for online because there's so many websites", he concludes. Having now illustrated a variety of ways in which the process of class conditioning is played out in young people's everyday life with digital media, in the next section, I explore processes of class positioning.

\section{Processes of class positioning}

The concept of class positioning sheds light on the process through which the habitus of different classes generates class-distinctive preferences, practices, and lifestyles. In this context, it calls our attention to how the symbolic dimensions of social class shape the digital media preferences and practices of young people and their parents according to perceived and subjectively felt class boundaries. It thus refers to the countless ways in which they are drawing on digital media as a symbolic resource for signifying class and performing the kind of boundary-work (Lamont, 1992) whereby class boundaries are (re)produced.

Interestingly, the process of class positioning seems to be at the bottom of the restrictive parental mediation strategies adopted by some of the families rich in cultural capital, rather than the class-conditioned lack of familiarity with digital media typical of parents poor in cultural capital. This is evident in how 16-year-old Carl explains why his parents were late to acquire broadband at home:

Well, my friends really liked computers and stuff like that. And when mum and dad noticed this, that they sat with the computer all the time, they got really scared and sort of "Oh, if you get broadband, you will sit with the computer all the time too, and you're going to lose all your contacts and you're not going to do anything reasonable with your life" [...] So they were cautious about it, they were pretty afraid of it. It was the same thing with digital TV. My friends were like real couch potatoes and sat in front of the TV all the time, and my parents thought it was terrible and that if we got digital TV, it would happen to us too, sort of. 
In the Swedish context, where Internet access is widespread and home computers are common goods, the choice of not acquiring the latest digital media technology might thus be a sign of distinction of those classes who can actually choose to abstain.

The process of class positioning is at work in the young men's narratives about their own digital media preferences and practices as well. For example, those rich in cultural capital carefully represent their digital gaming practices as moderate, social, and responsible, as opposed to the culturally devalued ways of gaming by "those staying up all night [...] wasting their social life" (Ian, 17 years old). Their media-related class-making also extends beyond gaming practices. When 16-year-old Nils talks about his Wikipedia habits, he simultaneously conveys an image of himself as an educated person, as opposed to those who would never voluntarily engage in such practices. In other words, he performs class:

If I'm bored, really bored [...] I usually go to Wikipedia and just sort of browse through a random article. Just for fun really [...] I have always considered myself quite well-read, and to learn gives me pleasure, so to speak. And I can get that from Wikipedia [...] It might sound extremely boring to others, but... No, but you might actually catch yourself doing really weird things when being really bored, suddenly you're just sitting and playing with something [...] I'm going to Wikipedia instead [...] Because I'm really thirsty for knowledge and I want to understand why things are the way they are and... like why did the king of Portugal stop Columbus from travelling? Such things.

The young men poor in cultural capital are also engaged in this kind of class-related boundary-work drawing on digital media. Generally sharing an unreserved interest in digital gaming, it is evident, for example, in their stories about gaming together during lessons - a carnivalesque way of opposing school culture, undermining teacher authority, and thus maintaining class boundaries between themselves and the educated class. It is evident also in how 17-year-old gaming-fan Simon reflects on whether certain digital media practices are generally ascribed with a higher cultural value than others:

Yes, I think so [...] I think that... there are probably not too many young people who use, like, news sites every day, or websites where you're supposed to tell your opinion, or what you think about politicians and shit like that, or elections and stuff like that. I don't think there are too many people using such websites. I think it's just the... posh people [mockingly] who make use of them. I really think it's that way.

By associating civic media practices (consuming news, debating politics) with the "posh people" of other classes - implying simultaneously that such practices are "not for the likes of him" (see Bourdieu, 1984: 471) - Simon is drawing on the space of digital media practices as a symbolic resource for recognising and representing his own position in social space.

Before turning to the conclusions, it is important to stress that the process of class positioning is linked to the process of class conditioning insofar as it bears witness to differences in objective living conditions. When Simon dissociates himself from online news and political debate, it speaks of his lack of cultural capital in the family, just as Nils's way of identifying himself as "quite well-read" indicates access to such capital. However, 
acknowledging this is neither to say that these processes are one and the same thing, nor that the process of class conditioning completely determines practices of class positioning.

\section{Conclusions}

I have explored in this article how social class shapes the conditions and configurations of digital media practice in the everyday life of young people in Sweden. Drawing on Bourdieusian theory and qualitative interviews with young people and parents, I have pointed out and exemplified two different but interrelated processes whereby this shaping is taking place: class conditioning and class positioning. Although difficult to separate in everyday practice, distinguishing between these processes conceptually makes it possible to identify different aspects of social class as a unified force structuring social life. As analytical constructs, they might thus contribute to a more nuanced understanding of how class makes a difference in young people's everyday life with digital media. They not only circumvent the risk of treating social class as a fixed set of socioeconomic variables by emphasising how class is continuously realised through social processes embedded in everyday contexts. They also sensitise us to how, for example, limited home Internet access, or the enactment of a restrictive parental mediation strategy, might in fact, depending on context, be the result of processes of either class conditioning or class positioning, which significantly alters its meaning. Finally, distinguishing between these processes, instead of simply talking about social class, explicitly acknowledges both the objective and subjective dimensions of class, which might be helpful in avoiding reductionist accounts that represent class as a matter of either raw material determinism or sheer symbolism (see Sayer, 2005).

In light of how processes of class conditioning and class positioning are played out in young people's everyday life with digital media, advancing a national Internet policy geared towards general welfare seems a complicated endeavour. This article shows that the policy-induced proliferation of home computers and Internet access has not abolished digital inequalities, but rather created a rich soil for new forms of class-making. As highlighted by the concept of class positioning, young people and parents draw on today's myriad of digital media devices and practices as a symbolic resource for communicating class and engaging in class-related boundary-work. Moreover, the wiring of Swedish households and schools has barely transformed the basic realities of social class, insofar as differences in objective conditions of existence - that is, economic and cultural capital (e.g., parental income and education) - still seem to shape young people's possibilities for using the Internet and developing various digital skills. While young people at a safe distance from material necessity can enjoy informal lessons in online information searching at home, those closer to it cannot expect the same kind of support, or even what Robinson and Schulz (2013) refer to as "individualised net time".

The current policy shift towards promoting media and information literacy, including digital skills, through formal schooling might thus bring unintended consequences. As media and information literacy in general, and digital skills in particular, are largely acquired informally by young people in their spare time, and the conditions of this acquisition are shaped by the materialities of social class, making them part of school curriculum runs the risk of institutionalising preexisting class differences, thus adding to the educational system's involvement in the reproduction of class as much as to its 
Class conditioning and class positioning in young people's everyday life with digital media

levelling of differences in life-chances. This is neither to say that a media policy geared towards promoting media and information literacy for all is in vain, nor that it should not be conducted through public education. On the contrary, a universalistic welfare state striving for an equality beyond minimal needs (Esping-Andersen, 1990) must advance such a policy, and public education is probably the chief means of doing so, as it includes all citizens. It is to say, however, that as long as it is not accompanied by a repaired politics of economic redistribution, our expectations of what it can achieve in terms of reduced inequality and increased social mobility should be modest.

\section{References}

Bourdieu, P. (1984). Distinction: A social critique of the judgement of taste. Cambridge, Massachusetts: Harvard University Press.

Bourdieu, P. (1986). The forms of capital. In J. G. Richardson (Ed.), Handbook of theory and research for the sociology of education (pp. 241-258). Westport, Connecticut: Greenwood Press.

Bourdieu, P. (1987). What makes a social class? On the theoretical and practical existence of groups. Berkeley Journal of Sociology, 32, 1-17. http://www.jstor.org/stable/41035356

Correa, T. (2016). Digital skills and social media use: How Internet skills are related to different types of Facebook use among 'digital natives'. Information, Communication \& Society, 19(8), 1095-1107. https:// doi.org/10.1080/1369118X.2015.1084023

Danermark, B., Ekström, M., Jakobsen, L., \& Karlsson, J. (2019). Explaining society: Critical realism in the social sciences. London: Routledge. https://doi.org/10.4324/9781351017831

Danielsson, M. (2014). Digitala distinktioner: Klass och kontinuitet i unga mäns vardagliga mediepraktiker [Digital distinctions: Class and continuity in young men's everyday media practices] [Doctoral dissertation, Jönköping University, Sweden]. http://urn.kb.se/resolve?urn=urn:nbn:se:hj:diva-24372

Davies, H. C., \& Eynon, R. (2018). Is digital upskilling the next generation our 'pipeline to prosperity'? New Media \& Society, 20(11), 3961-3979. https://doi.org/10.1177/1461444818783102

Erikson, R., \& Goldthorpe, J. H. (1992). The constant flux: A study of class mobility in industrial societies. Oxford: Clarendon Press.

Esping-Andersen, G. (1990). The three worlds of welfare capitalism. Cambridge: Polity Press.

Eynon, R., \& Geniets, A. (2016). The digital skills paradox: How do digitally excluded youth develop skills to use the internet? Learning, Media and Technology, 41(3), 463-479. https://doi.org/10.1080/174398 84.2014.1002845

Government Offices of Sweden. (2000). Ett informationssamhälle för alla: Prop. 1999/2000:86 [An information society for everyone: Proposition 1999/2000:86]. https://www.regeringen.se/rattsliga-dokument/ proposition/2000/03/prop.-1999200086/

Gui, M., \& Argentin, G. (2011). Digital skills of Internet natives: Different forms of digital literacy in a random sample of northern Italian high school students. New Media \& Society, 13(6), 963-980. https:// doi.org/10.1177/1461444810389751

Hargittai, E. (2010). Digital na(t)ives? Variation in Internet skills and uses among members of the "net generation". Sociological Inquiry, 80(1), 92-113. https://doi.org/10.1111/j.1475-682X.2009.00317.x

Hargittai, E., \& Hinnant, A. (2008). Digital inequality: Differences in young adults' use of the Internet. Communication Research, 35(5), 602-621. https://doi.org/10.1177/0093650208321782

Helsper, E., \& Eynon, R. (2013). Distinct skill pathways to digital engagement. European Journal of Communication, 28(6), 696-713. https://doi.org/10.1177/0267323113499113

Hollingworth, S., Mansaray, A., Allen, K., \& Rose, A. (2011). Parents' perspectives on technology and children's learning in the home: Social class and the role of the habitus. Journal of Computer Assisted Learning, 27(4), 347-360. https://doi.org/10.1111/j.1365-2729.2011.00431.x

Hort, S. E. O. (2014). Social policy, welfare state, and civil society in Sweden, volume I: History, policies, and institutions 1884-1988 (3rd ed.). Lund, Sweden: Arkiv förlag.

Internetstiftelsen [The Swedish Internet Foundation]. (2019). Svenskarna och internet 2019 [The Swedes and Internet 2019]. https://svenskarnaochinternet.se/app/uploads/2019/10/svenskarna-och-internet-2019-a4.pdf

Katz, V. S., \& Gonzales, C. (2016). Community variations in low-income Latino families' technology adoption and integration. American Behavioral Scientist, 60(1), 59-80. https://doi.org/10.1177/0002764215601712

Lamont, M. (1992). Money, morals, and manners: The culture of the French and American upper-middle class. Chicago: University of Chicago Press.

Livingstone, S. (2011). If everything is mediated, what is distinctive about the field of communication? International Journal of Communication, 5, 1472-1475. https://ijoc.org/index.php/ijoc/article/view/1356/620 
Livingstone, S., \& Helsper, E. (2007). Gradations in digital inclusion: Children, young people and the digital divide. New Media \& Society, 9(4), 671-696. https://doi.org/10.1177/1461444807080335

Livingstone, S., Mascheroni, G., Dreier, M., Chaudron, S., \& Lagae, K. (2015). How parents of young children manage digital devices at home: The role of income, education and parental style. EU Kids Online, LSE. http://eprints.lse.ac.uk/id/eprint/63378

Murdock, G., Hartmann, P., \& Gray, P. (1992). Contextualizing home computing: Resources and practices. In R. Silverstone, \& E. Hirsch (Eds.), Consuming technologies: Media and information in domestic spaces (pp. 146-160). London: Routledge. https://doi.org/10.4324/9780203401491

Nordicom. (2019). Nordicom-Sveriges mediebarometer 2018 [Nordicom-Sweden's media barometer 2018]. https://www.nordicom.gu.se/sv/system/tdf/publikationer-hela-pdf/nordicom_sveriges_mediebarometer_2018.pdf?file $=1 \&$ type $=$ node $\&$ id $=40345 \&$ force $=0$

North, S., Snyder, I., \& Bulfin, S. (2008). Digital tastes: Social class and young people's technology use. Information, Communication \& Society, 11(7), 895-911. https://doi.org/10.1080/13691180802109006

OECD. (2018). A broken social elevator? How to promote social mobility: Overview and main findings. http:// www.oecd.org/social/soc/Social-mobility-2018-Overview-MainFindings.pdf

Olsson, T. (2002). Mycket väsen om ingenting: Hur datorn och internet undgår att formas till medborgarens tekniker [Much ado about nothing: How the computer and the Internet miss their plight as tools of the citizen] [Doctoral dissertation, Uppsala University, Sweden]. http://urn.kb.se/resolve?urn=urn:nbn:se:uu:diva-2692

Pettersson, C. (2001). Datorer åt många: En studie om datorn som vardagsteknik och kunskapsverktyg [Computers for the many: A study about the computer as everyday technology and knowledge device] [Licentiate Thesis, Linköping University, Sweden]. http://urn.kb.se/resolve?urn=urn:nbn:se:liu:diva-34068

Prensky, M. (2001). Digital natives, digital immigrants part 1. On the Horizon, 9(5), 1-6. https://doi. org/10.1108/10748120110424816

Reay, D. (2004). Gendering Bourdieu's concept of capitals? Emotional capital, women and social class. In L. Adkins, \& B. Skeggs (Eds.), Feminism after Bourdieu (pp. 57-74). Boston: Wiley-Blackwell.

Robinson, L. (2009). A taste for the necessary: A Bourdieuian approach to digital inequality. Information, Communication \& Society, 12(4), 488-507. https://doi.org/10.1080/13691180902857678

Robinson, L., \& Schulz, J. (2013). Net time negotiations within the family. Information, Communication \& Society, 16(4), 542-560. https://doi.org/10.1080/1369118X.2013.777761

Sayer, A. (2005). The moral significance of class. Cambridge: Cambridge University Press.

Scheerder, A. J., van Deursen, A. J. A. M., \& van Dijk, J. A. G. M. (2019). Internet use in the home: Digital inequality from a domestication perspective. New Media \& Society, 21(10), 2099-2118. https://doi. org/10.1177/1461444819844299

Schofield Clark, L., Demont-Heinrich, C., \& Webber, S. A. (2004). Ethnographic interviews on the digital divide. New Media \& Society, 6(4), 529-547. https://doi.org/10.1177/146144804044333

Selwyn, N. (2004). Reconsidering political and popular understandings of the digital divide. New Media \& Society, 6(3), 341-362. https://doi.org/10.1177/1461444804042519

Snell, J. (2013). Dialect, interaction and class positioning at school: From deficit to difference to repertoire. Language and Education, 27(2), 110-128. https://doi.org/10.1080/09500782.2012.760584

Syvertsen, T., Enli, G., Mjøs, O. J., \& Moe, H. (2014). The media welfare state: Nordic media in the digital era. Ann Arbor, Michigan: University of Michigan Press. https://www.doi.org/10.3998/ nmw.12367206.0001.001

Therborn, G. (2018). Kapitalet, överheten och alla vi andra: Klassamhället $i$ Sverige - det rådande och det kommande [Capital, authority and the rest of us: Class society in Sweden - the present and the future]. Lund, Sweden: Arkiv förlag.

Tripp, L. (2010). 'The computer is not for you to be looking around, it is for schoolwork': Challenges for digital inclusion as Latino immigrant families negotiate children's access to the Internet. New Media \& Society, 13(4), 552-567. https://doi.org/10.1177/1461444810375293

van Deursen, A. J. A. M., Helsper, E., Eynon, R., \& van Dijk, J. A. G. M. (2017). The compoundness and sequentiality of digital inequality. International Journal of Communication, 11, 452-473. https://ijoc. org/index.php/ijoc/article/view/5739/1911

Warschauer, M. (2003). Technology and social inclusion: Rethinking the digital divide. Cambridge, Massachusetts: MIT Press.

Zillien, N., \& Hargittai, E. (2009). Digital distinction: Status-specific types of internet usage. Social Science Quarterly, 90(2), 274-291. https://doi.org/10.1111/j.1540-6237.2009.00617.x

(C) 2021 Nordicom and respective authors. This is an Open Access work licensed under the terms of the Creative Commons Attribution-NonCommercial-NoDerivatives 4.0 International Public licence (CC BY-NC-ND 4.0). To view a copy of the licence, visit https://creativecommons.org/ licenses/by-nc-nd/4.0/ 